\title{
Vivências e Reflexões Acerca de uma Proposta de Aconselhamento Nutricional com Gestantes para a Prevenção da Obesidade Infantil
}

\author{
Carliane Vanessa Souza Vasconcelos ${ }^{1}$, Sabrina Delany Frota de Sousa ${ }^{2}$
}

\begin{abstract}
RESUMO
A temática obesidade tem sido bastante discutida atualmente. É definida como uma Doença Crônica Não Transmissível e se caracteriza pelo acúmulo excessivo de gordura corporal, comprometendo a saúde. Acredita-se que a educação em saúde seja uma estratégia preventiva, posto que a educação é o processo pelo qual os clientes são efetivamente auxiliados a selecionar e seguir comportamentos desejáveis de nutrição e estilo de vida. A atuação do profissional nutricionista no acompanhamento das gestantes durante o pré-natal é uma necessidade. O objetivo deste estudo é analisar os efeitos da prática educativa em saúde centrados em gestantes buscando a prevenção da obesidade infantil desde a concepção. Trata-se de um estudo descritivo de abordagem qualitativa a partir de uma observação incorporada. A amostra incluiu gestantes acompanhadas pelo Centro de Saúde da Família, com idades entre 13 e 33 anos. As reuniões iniciais com o grupo nos proporcionaram levantar uma série de observações no que se refere à convivência e aceitação da gestante em enfrentar a obesidade infantil como uma doença. Inicialmente elas tinham conhecimentos básicos sobre alimentação no período gestacional e alimentação do bebê. Em relação ao Aconselhamento Nutricional, a maioria das gestantes não tinha participado de um grupo em que recebiam orientação. A pesquisa mostrou-se útil para a melhoria do grau de conhecimento das participantes sobre o enfrentamento da obesidade como uma doença e a adoção de uma alimentação adequada com enfoque no período gestacional e alimentação de crianças menores de dois anos.
\end{abstract}

Palavras-chave: Obesidade. Aconselhamento. Gestante.

\section{EXPERIENCES AND REFLECTIONS ON A PROPOSAL FOR NUTRITION COUNSELING} WITH PREGNANT WOWEN FOR THE PREVENTION OF CHILDHOOD OBESITY

\begin{abstract}
The subject area obeseness has been widely discussed nowadays. It is defined as a Non Contagious Chronic Disease and it is characterized by the excessive congestion of the fat content of the body, damaging the health. It is believed that health education is a preventive strategy, since education is the process by which clients are effectively assisted in selecting and implementing desirable behaviors of nutrition and lifestyle. And the performance of the nutritionist in the follow-up of pregnant women during prenatal care is a necessity. The objective of this study is to analyze the effects of educational practice on client-centered health in pregnant women to prevent childhood obesity from conception. It is a descriptive study of a qualitative approach based on an incorporated observation. The sample included pregnant women accompanied by the Family Health Center, aged 13 to 33 years. The initial meetings with the group provided us with a series of observations regarding the coexistence and acceptance of the pregnant woman in facing childhood obesity as a disease, who initially had basic knowledge about gestational feeding and baby feeding. Regarding Nutrition Counseling, most of the pregnant women had not participated in a group in which they received orientation. The research was useful to improve the participants' level of knowledge about coping with obesity as a disease and the adoption of adequate food with focus on the gestational period and feeding of children under two years.
\end{abstract}

Keywords: Obesity. Counseling. Pregnant.

Recebido em: 8/10/2017

Aceito em: 18/2/2018

\footnotetext{
Nutricionista pelas Faculdades Inta, Sobral-CE. Especialista em Nutrição Clínica, Esportiva e Fitoterápica pelas Faculdades Uninta, Sobral-CE. Especialista em caráter de Residência Multiprofissional em Saúde da Família pela Universidade do Vale Acaraú e Escola de Saúde, Sobral-CE. carlianeprata@hotmail.com

${ }^{2}$ Nutricionista pelas Faculdades Inta, Sobral-CE. Especialista em Nutrição Clínica e Esportiva pelo IPGS, Fortaleza-CE. Mestranda em Biotecnologia pela Uninta, Sobral-CE. sabrina.desousa@gmail.com
} 


\section{INTRODUÇÃO}

A temática de obesidade tem sido bastante discutida atualmente. É definida como uma Doença Crônica Não Transmissível (DCNT) e se caracteriza pelo acúmulo excessivo de gordura corporal comprometendo a saúde. É cada vez mais comum, e sua prevalência já atinge proporções epidêmicas. Uma preocupação são os riscos de doenças associadas, tais como diabetes, doenças cardiovasculares (DCV) e alguns cânceres. É importante o conhecimento das comorbidades frequentes para permitir o diagnóstico precoce e o tratamento destas condições, que proporcionará a identificação precoce e a avaliação de risco, de forma que as intervenções adequadas possam ser realizadas para reduzir a mortalidade associada (ASSOCIAÇÃO..., 2011).

Em se tratando do quadro clínico, podemos afirmar que um indivíduo adulto que apresenta Índice de Massa Corporal - IMC (peso em quilos dividido pela altura em metros ao quadrado) - igual ou superior a $30 \mathrm{~kg} / \mathrm{m}^{2}$, deva ser classificado como obeso (BRASIL, 2011). Essa observação pode ser feita independentemente de sexo e idade. Em crianças e adolescentes usualmente é realizada a avaliação nutricional por meio de critérios estatísticos que expressam a classificação dos índices antropométricos. Faz parte da análise do quadro clínico o IMC associado ao Escore-Z (BRASIL, 2011).

Dados epidemiológicos demonstram que a obesidade acomete as sociedades contemporâneas e se tornou uma epidemia em países desenvolvidos e em desenvolvimento. No Brasil, a prevalência do excesso de peso atinge $56,9 \%$ das pessoas com mais de 18 anos, ou seja, têm um índice de massa corporal (IMC) igual ou maior que 25 . Além disso, $20,8 \%$ das pessoas são classificadas como obesas por terem IMC igual ou maior que 30. Em relação à alimentação das crianças de até 2 anos, a pesquisa constatou que $60,8 \%$ já comem biscoito, bolacha ou bolo e $32,3 \%$ tomam refrigerante e suco artificial (INSTITUTO..., 2014). Esses alimentos, considerados ultraprocessados, são ricos em açúcares, gorduras e sal e predispõe a Doenças Crônicas Não Transmissíveis (DCNTs), como a Obesidade, Diabetes Mellitus e Hipertensão Arterial Sistêmica (HAS) (BRASIL, 2014).

De acordo com os dados da Sala de Apoio à Gestão Estratégica (Sage) do Ministério da Saúde, em toda a região brasileira houve um aumento de óbitos por obesidade e outras formas de superalimentação no período de 10 anos (2001 a 2010). Neste espaço de tempo, a média de óbitos no Brasil foi de 1.416,2. Dentre os anos de maior valor registrado podemos identificar 2009, com 2.035 mortes, e 2010, com 2.106. A média de óbitos no Ceará foi de 30,3 , e em 2008 foi observado o maior número, com 51 mortes. No local de estudo a média foi de 0,2 óbitos, quando apresentou 2 casos de morte apenas em 2009 (BRASIL, 2014).

A necessidade de aconselhamento nutricional logo na gestação é importante por ser um período que demandam cuidados especiais, principalmente na assistência à saúde e à nutrição. Determinadas medidas devem ser adotadas para que a gestante tenha hábitos mais saudáveis, como o peso da massa corporal adequado para a estatura, ganho ponderal no período gestacional, consumo de alimentos variados, suplementação apropriada de micronutrientes e o não uso de álcool e/ou cigarro ou qualquer outra substância danosa (ROSSI; MOREIRA; RAUEN, 2008).

A atuação do profissional nutricionista no acompanhamento das gestantes durante o pré-natal é uma necessidade, estando ele habilitado, segundo a Lei n. 8.234 (BRASIL, 1991), para prestar assistência e educação nutricional a coletividades ou indivíduos, sadios ou enfermos, em instituições públicas e privadas e em consultório de nutrição e dietética. O profissional de nutrição está apto a desempenhar suas funções de maneira multidisciplinar com a equipe de saúde já inserida no pré-natal. A prevenção consiste em ações, como o acompanhamento do estado nutricional da gestante, a promoção do aleitamento materno, o incentivo à alimentação saudável e balanceada, a alimentação das crianças menores de dois anos e o estímulo à atividade física.

O objetivo deste trabalho é apresentar as principais vivências e reflexões acerca de uma proposta de aconselhamento nutricional com gestantes acompanhadas pela Equipe de Saúde da Família e Núcleo de Apoio à Saúde da Família em um município da mesorregião do Noroeste cearense, para prevenção da obesidade infantil desde a concepção. A motivação para esta pesquisa surgiu ao refletir sobre os problemas nutricionais que afetam a infância, sobretudo a obesidade infantil. A pauta deste estudo está na importância de um recurso no meio nutricional para esclarecer acerca da prevenção da obesidade infantil, dando ênfase ao período gestacional e alimentação de crianças menores de dois anos.

\section{METODOLOGIA}

Trata-se de um estudo descritivo de abordagem qualitativa a partir de uma observação incorporada. Aqui serão analisadas as vivências e experiências do 
aconselhamento nutricional em saúde em gestantes acompanhadas pela Equipe de Saúde da Família (Sede 1 e 2) em um município da mesorregião do Noroeste cearense, na perspectiva de prevenção da obesidade infantil desde a concepção.

O processo de abordagem qualitativa se mostra distinto dos demais tipos de pesquisa por investigar o emprego de diferentes concepções filosóficas, estratégias, métodos de coleta, análise e interpretação dos dados. Os procedimentos qualitativos utilizam dados de texto e imagem, observações e entrevistas e protocolo planejado antes de ir para campo para o registro de dados (CRESWELL, 2010). Esse método não pode ser traduzido em números; não há uso de estatísticas; o pesquisador é considerado o instrumento-chave para esse tipo de pesquisa; ele observa o ambiente, interpreta e atribui significados (FERREIRA, 2011).

A Observação Incorporada visa a constituir-se em um relato da experiência do indivíduo no ambiente, de uma forma mais atenta, aberta e consciente de suas sensações e emoções. Não é apenas um método; é uma atitude, um novo olhar em que o pesquisador vai expressar-se por meio de um diário de campo, e irá relatar as suas sensações, emoções e experiências vivenciadas durante toda a pesquisa (FIGUEIREDO; MACHADO; SANTOS, 2007). A observação incorporada pode ser definida como uma sequência de associações do contexto em que o observador está inserido, e esse espaço configura um ponto-de-vista aproximado e particular da experiência vivenciada (RHEINGANTZ et al., 2009).

Para desenvolver um bom trabalho de campo, os autores apresentam em seus estudos um roteiro de como fazer a observação incorporada. Evidenciam alguns instrumentos que devem ser utilizados, tais como prancheta, papel de rascunho, lápis macio, caderno de campo, máquina fotográfica e gravadora. Neste foi utilizado diário de campo, gravadora e máquina fotográfica, em que fizeram registro de voz, imagens e escrita de suas observações, afetações e vivências.

O estudo foi realizado em um Centro de Saúde da Família em um município da mesorregião do Noroeste cearense. $O$ referido município localiza-se a $258,5 \mathrm{~km}$ da capital Fortaleza, com população estimada de 22.479 habitantes e área de 329, $945 \mathrm{~km}^{2}$. Em relação às Unidades de Saúde, o município dispõe de um Hospital Geral, oito Centros de Saúde/Unidades Básicas de Saúde, um Centro de Atenção Psicossocial (Caps), um Núcleo de Apoio à Saúde da Família (Nasf), um Centro de Referência Especializado de Assistência Social (Creas) e um Centro de Referência de Assistência Social (Cras) (INSTITUTO..., 2010).

De acordo com os profissionais, os principais problemas de saúde são: Doenças Crônicas Não Transmissíveis (DCNTs), diarreia e gripe. A equipe reúne-se mensalmente para avaliar e discutir novas estratégias. O Centro de Saúde possui grupos de apoio para gestantes e idosos. $O$ grupo de gestante foi articulado em parceria com o Núcleo de Apoio à Saúde da Família (Nasf).

O Nasf foi instituído no município em 2009, e tem como objetivo prestar apoio à equipe de saúde por intermédio de projetos terapêuticos, grupos, visitas domiciliares, oficinas e outros projetos e ações propostos e desenvolvidos em parceria com as equipes. O grupo de gestantes foi composto por dez mães, que receberam orientações dos profissionais de saúde e das pesquisadoras para melhorar o conhecimento das mesmas sobre como prevenir a obesidade desde a concepção.

A amostra incluiu gestantes que são acompanhadas pelo Centro de Saúde da Família, com idades compreendidas entre os 13 e os 33 anos. $O$ convite às gestantes para a participação do Projeto se deu por meio de visitas domiciliares das pesquisadoras junto com os Agentes Comunitários de Saúde de cada área. As gestantes foram informadas sobre a criação do grupo e os temas a serem discutidos em determinada reunião, local e horário. Os encontros ocorreram nas segundas-feiras, totalizando cinco momentos no ano de 2013. As reuniões aconteceram no Nasf, com duração de, no máximo, três horas.

Foram cinco encontros educativos sobre alimentação saudável e bons hábitos de vida no período gestacional e alimentação de crianças menores de dois anos para prevenção da obesidade infantil.

Após o período de atividades realizadas durante a inserção das pesquisadoras no território, foram registradas vivências e reflexões a respeito desta experiência em um diário de campo. Para a apresentação dos resultados foram utilizadas figuras representativas, expondo as vivências e reflexões diante do processo educativo, que deu destaque para o período gestacional e alimentação de crianças menores de dois anos, com a pretensão de prevenir a obesidade infantil desde a concepção.

A presente pesquisa não necessitou apreciação do Comitê de Ética em Pesquisa com Seres Humanos, por se tratar de uma observação incorporada em que foram relatadas, por meio de um diário de campo, as 
vivências e reflexões adquiridas durante esses encontros. Mesmo assim, para a realização do presente estudo, no intuito de formalizar o processo científico e atribuir um caráter profissional à pesquisa, foram respeitados os princípios de uma pesquisa científica e solicitada a anuência da Secretaria de Saúde do referido município.

\section{RESULTADOS E DISCUSSÕES}

As reuniões foram coordenadas pelas pesquisadoras, com a participação dos profissionais de saúde da Estratégia Saúde da Família (ESF) e Nasf. Trabalhou-se a temática para prevenção da obesidade infantil desde a concepção. Para isso, usou-se Aconselhamento Nutricional Verbal Centrado no Cliente. Ora utilizou-se métodos expositivos, ora debates e discussões. Durante as atividades foram empregados instrumentos usuais de registro, tais como caderno de campo, lápis macio, caneta, máquina fotográfica e filmadora. Após cada reunião registrava-se por escrito as observações do campo e assistia-se aos vídeos, o que muito contribuiu para os resultados desta pesquisa.

As atividades foram realizadas em uma sala do Nasf com a presença das pesquisadoras, profissionais da ESF e Nasf e grupos de até dez gestantes. Em todos os encontros tivemos variações no número de gestantes.

\section{Primeiro Encontro: apresentação do projeto}

Nesse primeiro momento com o grupo objetivou-se apresentar as propostas do trabalho que se iniciava e entrosar as participantes com a pesquisadora e com os profissionais de saúde do Nasf e da ESF. Foi desenvolvida, então, uma dinâmica de apresentação em que as gestantes expressaram seus sentimentos pelo bebê (Figura 1) por meio de um painel interativo (foto de um bebê e palavras de afeto). A exposição era seguida de nome, meses de gestação, se era a primeira gestação e o que mais almejasse expressar. Logo após elas escolhiam uma palavra que representava um sentimento afetivo para colar perto da figura de um bebê.

Figura 1 - Dinâmica "sentimento afetivo pelo bebê"

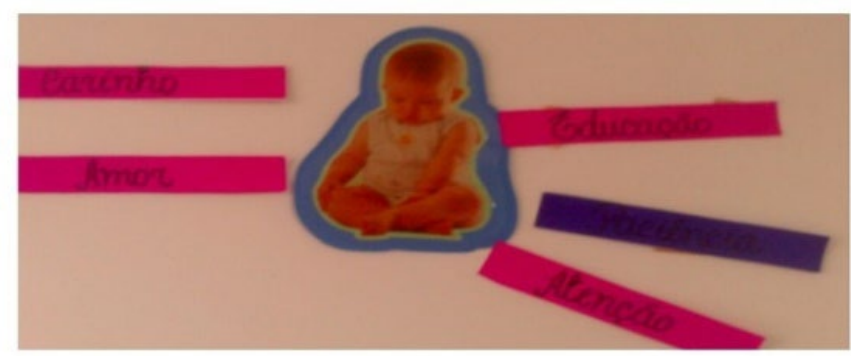

As gestantes demonstraram os sentimentos mais variados de carinho e amor pelos bebês que aguardavam. Notava-se isso na expressão, nos gestos, no tom da voz e não somente na fala ou na palavra que fora escolhida. No estudo de Piccinini et al. (2008), as mães referiram sentir a gravidez como uma conquista, e demonstraram sentimentos de conformidade, inadequação, estranhamento e intensificação nos sentimentos.

Após a apresentação em linhas gerais do que tratava o projeto, as participantes foram questionadas sobre quais eram as suas expectativas. Todas as gestantes demonstraram interesse sobre o tema. Neste dia houve a presença de 5 gestantes, com faixa etária entre 13 e 33 anos, sendo a maioria adolescentes. 0 encontro teve duração de 40 minutos.

\section{Segundo Encontro: conversando sobre obesidade infantil e alimentação da gestante}

A equipe de saúde expôs que apreciou bastante o projeto, por entender a obesidade como uma doença que já afeta crianças de maneira significativa. Neste encontro foram discutidas a obesidade infantil e a importância de preveni-la desde a concepção.

A ferramenta utilizada foi contação de histórias (Figura 2), montagem de pirâmide alimentar da gestante e, em seguida, assistiram parte de um documentário (MUITO ALÉM DO PESO, 2012). Primeiramente foi exposta a figura de uma gestante. Ao observar a figura foi contada a história de uma gestante adolescente que esperava seu primeiro bebê. Nessa história foi enfocada a definição da obesidade infantil, as causas e complicações da doença e os fatores de risco relacionados à gestante e ao bebê, além da sua forma de prevenção.

Figura 2 - Contação de histórias

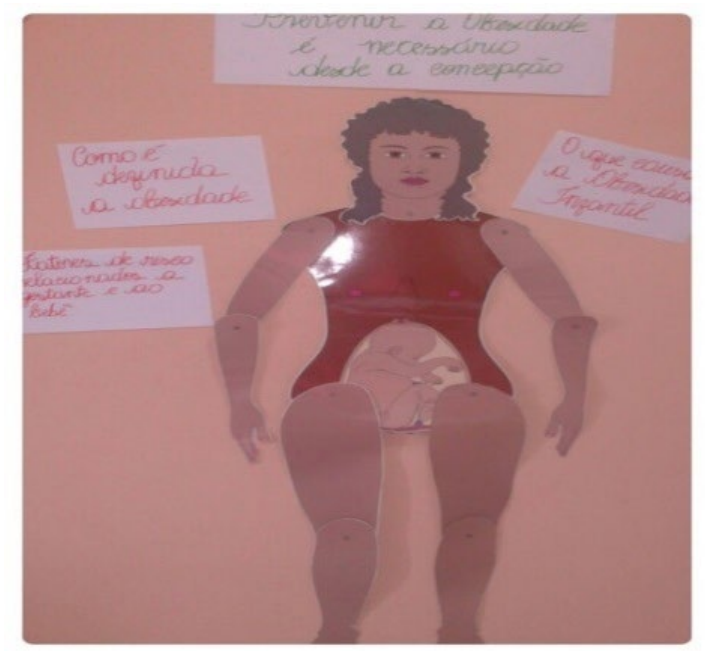


Discutiu-se também sobre a importância de uma alimentação saudável durante o período gestacional e sua relação com a saúde do feto. As gestantes montaram uma pirâmide alimentar e conheceram um pouco melhor os grupos e porções alimentares que devem fazer parte da sua dieta usual. Neste momento foi explicado quanto ao ganho ponderal de peso, que deve estar de acordo com o estado nutricional pré-gestacional (IOM, 2009 apud ANDRETO et al., 2006).

As gestantes assistiram a um documentário que as fez refletir sobre como estava a sua alimentação. Um ponto importante ressaltado foi quais alimentos serão inseridos na dieta de seus bebês após os seis meses de aleitamento materno exclusivo, em razão dos problemas de saúde que acometem crianças (MUITO ALÉM DO PESO, 2012).

Neste caso, percebeu-se certa dificuldade das participantes para enfrentar a obesidade infantil como uma doença. No decorrer das discussões e ao assistiram o documentário, porém, elas ficaram chocadas com as consequências sérias que a obesidade traz ( $\mathrm{Fi}$ gura 3). As gestantes perceberam, então, a importância de se prevenir a obesidade, ao observar crianças e adolescentes acometidas por tais doenças.

Figura 3 - Documentário

"Muito Além do Peso" (2012)

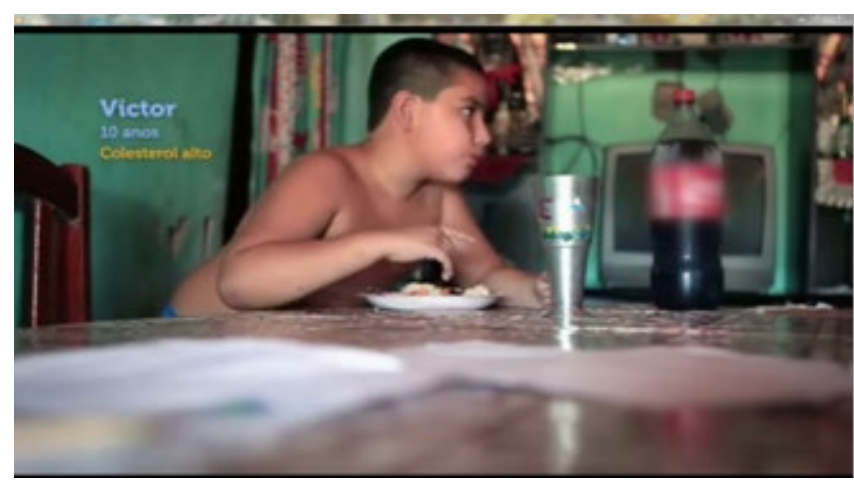

Antes e depois da intervenção foram feitas perguntas de maneira informal para o grupo por meio de uma dinâmica representada por plaquinhas de maçã verde (verdadeiro) e vermelha (falso) (Figura 4). As gestantes foram questionadas sobre a problemática da obesidade infantil, se já conheciam ou ouviram falar sobre a doença. Metade do grupo respondeu que sim. Em se tratando das causas da obesidade infantil, a resposta obtida foi que a maioria das gestantes não sabia. Em relação aos fatores de risco que estão relacionados à gestante e ao bebê, todas responderam que não conheciam ou ouviram falar.
Figura 4 - Dinâmica das plaquinhas de maçã verde (verdadeiro) e vermelha (falso)

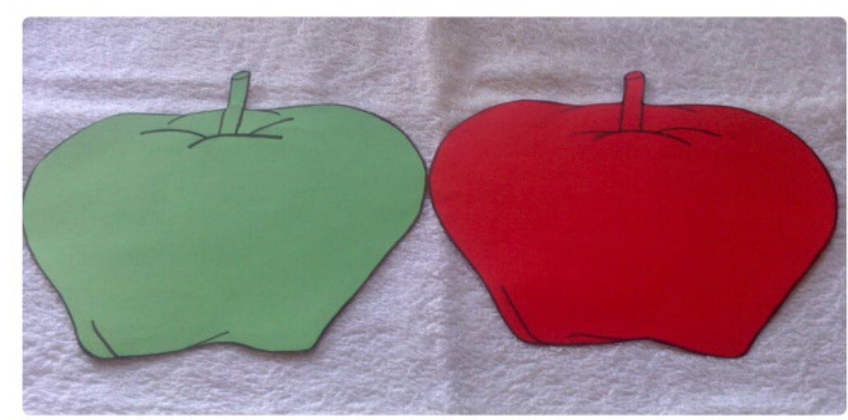

Neste encontro as gestantes receberam um panfleto sobre os dez passos da alimentação saudável do Ministério da Saúde. Houve a presença de dez gestantes, com faixa etária entre 13 e 33 anos, com duração de 2 horas.

\section{Terceiro Encontro: aleitamento materno e ativi-} dade física fazem bem para o bebê e para você

Na ocasião foram abordados dois pontos de total importância na prevenção da obesidade infantil: incentivo ao aleitamento materno e atividade física na gestação. Como de costume, iniciou-se com a dinâmica representada por plaquinhas de maçã verde (verdadeiro) e vermelha (falso), (Figura 4). As gestantes foram questionadas sobre a importância do aleitamento materno em quatro aspectos: bebê, mamãe, família e comunidade. Foi observado que as gestantes davam importância ao aleitamento materno exclusivo, entretanto nem todas sabiam definir vantagens desse aleitamento.

O grupo participou também da dinâmica filho esperado, na qual recebiam uma boneca e tinham o primeiro contato com o seu bebê. As gestantes trataram a boneca como se já fosse a sua filha, escolhendo o nome e informando se iria amamentar e qual a vantagem desse aleitamento nos aspectos já mencionados. Para a Organização Mundial da Saúde (OMS) e para a Sociedade Brasileira de Pediatria, "a prática de amamentação tem salvado muitas crianças por ano, promovendo e prevenindo contra as infecções, além da amamentação exclusiva ser importante sob o ponto de vista nutricional" (SOCIEDADE..., 2012).

Com tudo isso, é possível observar nas falas das gestantes que, ao serem questionadas se pretendem amamentar exclusivamente até os seis meses, as mesmas responderam que sim; apresentaram dificuldades, entretanto, em relatar as vantagens do aleitamento materno exclusivo, mencionando benefícios somente para o bebê. 
De acordo com o Ministério da saúde, é importante amamentar porque o bebê recebe todos os anticorpos da mãe para a proteção contra diarreia e infecções, e diminui riscos de alergias, colesterol alto, diabetes e obesidade. A amamentação favorece ainda o vínculo mãe e filho e ajuda a criança a desenvolver-se bem, física e emocionalmente. A amamentação é um excelente exercício para o desenvolvimento da face da criança, importante para que ela tenha dentes fortes, desenvolva a fala e tenha uma boa respiração (Figura 5).

Amamentar é bom não apenas para a saúde do bebê, mas também para a saúde da mulher. $O$ sangramento pós-parto diminui, assim como as chances de desenvolver anemia, câncer de mama e de ovário, diabetes e infarto agudo do miocárdio. A mulher que amamenta perde mais rápido o peso que ganhou durante a gestação.

Figura 5 - Incentivo ao aleitamento materno exclusivo

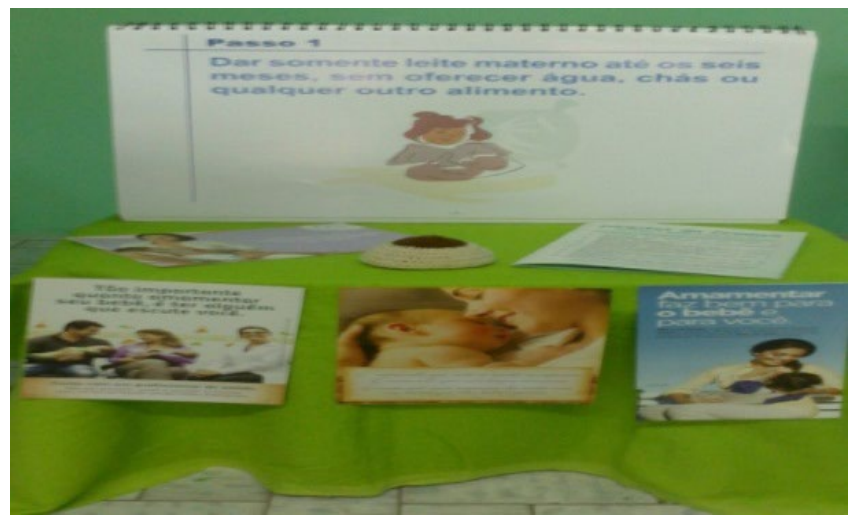

A educadora física do Nasf, por meio de uma roda de conversa, apresentou a importância da atividade física programada e moderada no período gestacional. Em seguida, as gestantes foram convidadas a fazer alongamentos e incentivadas a fazer algum tipo de exercício, como caminhadas e hidroginástica. De acordo com o Consenso Latino Americano de Obesidade (COUTINHO, 1999), a prevenção está em evitar o ganho de peso excessivo durante a gestação (o ideal é de 10 a $12 \mathrm{~kg}$ ).

Nesta ocasião as gestantes receberam panfletos sobre a importância do aleitamento materno do Ministério da Saúde. Teve a presença de oito gestantes, com faixa etária entre 13 e 33 anos, com duração de 2 horas.

\section{Quarto Encontro: alimentação complementar}

Nesse dia discutiu-se sobre alimentação complementar. Antes e depois da intervenção foram feitas perguntas de maneira informal para o grupo por meio da dinâmica das maçãs (Figura 4). As gestantes foram questionadas sobre o que é alimentação complementar, se conheciam os alimentos que devem ser introduzidos e como deveria ser o posicionamento e utensílios utilizados na preparação.

Em relação ao conhecimento sobre o que é a alimentação complementar, todas levantaram plaquinha verde, demonstrando saber sobre o assunto a ser discutido. Já quando se questionou sobre escolha dos alimentos, porções e utensílios, houve mais plaquinhas vermelhas do que verdes. Isso evidenciou dúvidas das mamães.

Após esse momento, iniciaram-se os trabalhos para conhecer um pouco mais sobre alimentação complementar. Primeiramente realizou-se uma dinâmica para a escolha de utensílios para utilizar na preparação da alimentação complementar. As gestantes precisariam entrar em consenso para a escolha dos utensílios. Puseram pontos positivos (polegar positivo na cor verde) e pontos negativos (polegar negativo na cor vermelha) em objetos como liquidificador e peneira, apresentando dificuldade, pois esses utensílios não são recomendados por diminuir o conteúdo de fibras, importantes para estimular o peristaltismo intestinal, favorecendo o aparecimento de constipação intestinal, além de ser fonte de contaminação (MARCONDES et al., 2002).

\section{Figura 6 - Utensílios utilizados na alimentação complementar}

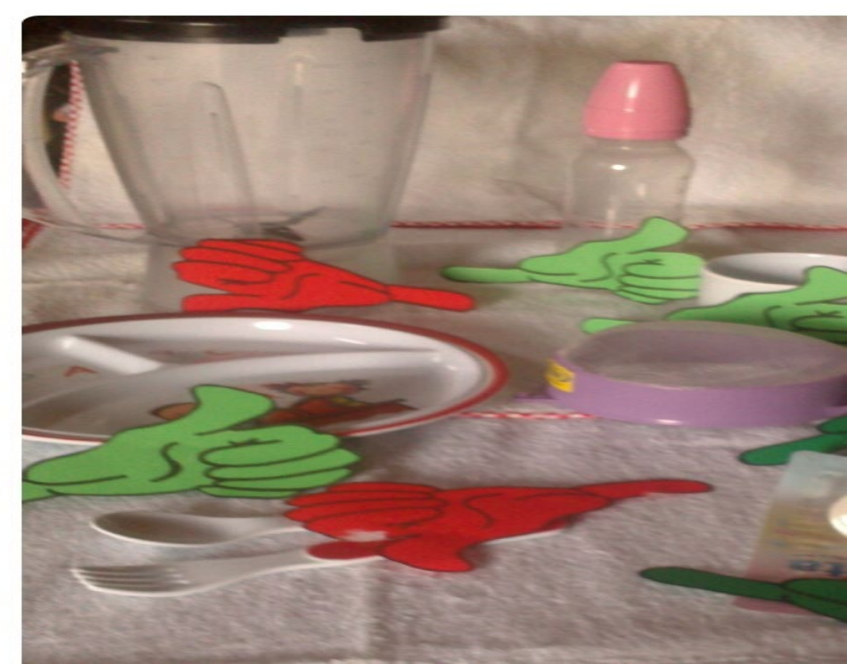

Em seguida, realizou-se a dinâmica sinal da boa alimentação (Figura 7), em que estavam expostos em uma mesa diversos alimentos, como seio em crochê representando o leite materno, sopa, frutas, mel, iogurte, arroz, feijão, carne, refrigerante, salgadinho, entre outros, e em outra mesa tínhamos toalhas na cor verde, amarela e vermelha com placas com ima- 
gem da criança e a fase em que ela se encontrava (até 6 meses, de 7 meses a 1 ano e de 13 meses a menor de dois anos).

As gestantes foram divididas em grupos de três, e cada grupo ficou responsável por um sinal. No sinal verde que deveria conter apenas o seio em crochê representando o leite materno exclusivo, as mães acrescentaram diversos outros alimentos, inclusive água. No sinal amarelo, as gestantes colocaram apenas frutas, sem estarem na consistência adequada. No sinal vermelho, as gestantes colocaram pão em uma porção muito grande, fizeram um prato com arroz, feijão e carne, porém não puseram salada. Em seguida foi reorganizada a mesa colocando na ordem correta.

Figura 7 - Dinâmica "Sinal da boa alimentação"

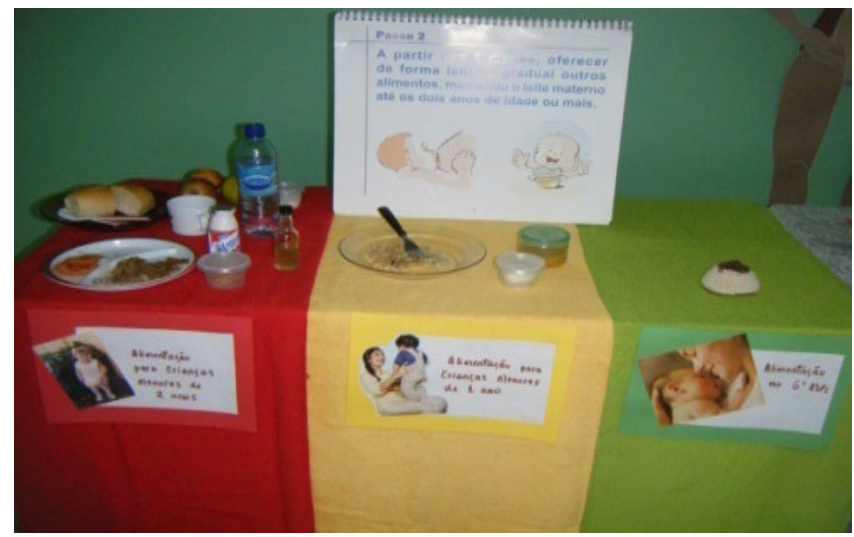

O Aconselhamento Nutricional é essencial para a prevenção da obesidade infantil porque pode evitar possíveis consequências que essa doença pode acarretar na idade adulta. Para a prevenção da obesidade infantil é importante retardar alimentos farináceos, evitar alimentos muito doces, fortalecer a atividade física, controlar e vigiar constantemente o peso corporal, promover educação nutricional e hábitos de vida saudáveis, e enfatizar que a obesidade é uma enfermidade de difícil cura e que todos devem lutar por sua prevenção (COUTINHO, 1999).

Segundo Kiess et al. (2001 apud SOARES; PETROSKI, 2003), "a prevenção deve começar bem cedo, de preferência na fase intrauterina. A estratégia deve ser elaborada juntamente com a equipe multidisciplinar (médico, nutricionista e educador físico), para que durante a gravidez a mulher realize atividade física moderada e execute a alimentação adequada tanto para o desenvolvimento do bebê, quanto para o seu bem-estar".

Nesse dia as gestantes receberam uma cartilha explicativa elaborada pelas pesquisadoras, utilizando como referência o Manual de Obesidade na Infância e na Adolescência da Sociedade Brasileira de Pediatria
(SOCIEDADE..., 2012). Com essa cartilha as gestantes poderão relembrar todos os pontos abordados durante os encontros. A reunião contou com a presença de nove gestantes, com faixa etária entre 13 e 33 anos, com duração de 2 horas. Após cada intervenção educativa foi aplicada novamente a dinâmica inicial da maçã, para perceber uma possível mudança no grau de conhecimento das participantes.

\section{Quinto Encontro: verbalizando as emoções}

O último encontro proporcionou um momento para dar adeus por meio da verbalização das emoções. As gestantes receberam papel e caneta e escreveram uma carta de despedida ao grupo. Por meio dessa carta, as mesmas deviam expressar os seus sentimentos por participar das reuniões, o que foi mais importante, se gostaram ou não de participar do grupo, se iriam sentir saudade e o que mais quisessem acrescentar. Em seguida as cartas foram lidas em voz alta pelas próprias autoras, demonstrando os sentimentos, reflexões e vivências das gestantes ao fim do encontro.

No relato das gestantes percebemos o quanto elas gostaram de ter profissionais que estavam à disposição para conversar, dar orientações, trocar experiências. A maioria evidenciou ter gostado muito e que não teria como não gostar, por ter aprendido coisas necessárias sobre o seu bebê, e ainda ressaltaram a importância de continuar com o grupo para outras mamães terem a mesma oportunidade.

O sentimento de pena por chegar ao fim estava evidenciado nos rostos de cada uma, não somente para as pesquisadoras ou membros da equipe de saúde, mas também entre as participantes. Elas trocaram muitas experiências, principalmente as que já tinham outros filhos. As mamães de primeira viagem ouviam atentamente, por saber da experiência e dificuldades enfrentadas que elas já tinham passado. Com isso, ficava o sentimento de agradecimento.

Para uma delas foi expressado o apreço por conhecer algo novo, pelo fato de no seu primeiro filho não ter tido essa oportunidade; ficou o sentimento emocionado de muita saudade; essa palavra estava em todas as falas. Foi enfatizado o gostar de ter passado esses dias juntas, de terem aprendido algo que não sabiam, que nunca ouviram ninguém falar diretamente para elas.

Uma gestante que já é mãe de duas filhas, sendo uma casada, demonstrou ter sido muito especial os encontros para ela. Relatou que, mesmo sendo experiente, havia muitas coisas que não sabia; achou 
muito proveitoso e expressou saudades. Demonstrou ainda que, para além do aprendizado, é um momento de diversão e de expressarmos nossas curiosidades e ansiedades umas com as outras; a mesma espera que o grupo continue.

Uma gestante chamou atenção ao expressar a falta que os encontros iriam fazer para ela, pois no próximo ano não poderia continuar porque já terá dado a luz ao seu filho. Isso demonstra a importância de dar continuidade na assistência, formando grupos de puérperas. Dessa maneira, se observaria mais simultaneamente as dificuldades enfrentadas, conversando sobre possíveis soluções e oferecendo apoio multiprofissional.

As gestantes relataram ter gostado muito de participar do grupo pela oportunidade de aprender coisas sobre a sua saúde e a do seu bebê, e, sobretudo, de terem feito amizades e poder trocar experiências com as outras mães. Para o encerramento foram entregues kits de higiene para o bebê e uma foi feita uma pequena confraternização com o grupo, junto com os profissionais de saúde e as pesquisadoras.

Considerando todo o tempo de observação incorporado, podemos relatar um resultado satisfatório. A convivência durante esses encontros com o grupo criou um vínculo de comprometimento e afetividade. As trocas foram intensas ao repassar o conteúdo e no desejo de aprender das participantes. Tanto o grupo quanto a equipe do Nasf demonstrou um apreço pela temática e pela maneira como foi discutida.

As reuniões iniciais do grupo nos proporcionaram levantar uma série de observações no que se refere à convivência e aceitação da gestante em enfrentar a obesidade infantil como uma doença. As gestantes demonstraram muito interesse em aprender algo novo, em virtude do amor incondicional que têm pelos seus bebês que ainda se encontram em seu ventre.

Observamos, inicialmente, que seus conhecimentos sobre alimentação no período gestacional e alimentação do bebê menor de dois anos eram básicos. Muito do que sabiam eram informações repassadas por suas mães, avós e/ou televisão.

Em relação ao Aconselhamento Nutricional, a maioria das gestantes não tinha participado de um grupo em que recebiam orientação, e demonstraram que um acompanhamento nutricional é de grande relevância para conhecer os cuidados que precisam ter durante esse período e, posteriormente, na alimentação de seus filhos. Segundo Delfino et al (2004), "o grupo de gestantes é o ambiente micro, e dinâmico, que objetiva a promoção da saúde integral individualcoletiva das gestantes, mediada pelas interações que nele ocorrem".

As estratégias adotadas nos encontros de Aconselhamento com o grupo demonstraram ter sido eficazes, considerando que, ao final, quase a totalidade das gestantes adquiriu conhecimentos adequados sobre alimentação e nutrição da gestante e do bebê. Assim, as ações propostas proporcionaram um incentivo para a prevenção da obesidade desde a concepção. A utilização de recursos auxiliares e de uma linguagem apropriada na prática educativa, com ênfase de apresentar atitude na hora de amamentar, escolher os grupos alimentares, formas de preparo, teve por objetivo fortalecer e encorajar as gestantes a saber o quanto é difícil, mas que é possível colocar em prática tudo o que foi visto.

Sabe-se atualmente da importância da alimentação saudável para a promoção da saúde. Em um estudo que objetivava avaliar a qualidade global da dieta em uma amostra de gestantes, foi evidenciado que a qualidade da dieta da maioria das gestantes foi classificada dentro do ponto de corte "precisando de melhorias", o que mostra a necessidade de se trabaIhar mais especificamente com educação alimentar nesse ciclo da vida (MELERE et al., 2013).

Os limites do estudo incluem o pequeno número de participantes e o curto período de Acompanhamento Nutricional para a avaliação do programa educativo. Considerando-se, entretanto, que a proposta atual foi capaz de proporcionar melhora no grau de conhecimento das gestantes, espera-se que tais benefícios possam também ser observados em ambientes e grupos semelhantes.

Além disso, a ausência do profissional nutricionista compondo a equipe do Nasf é um obstáculo, uma vez que o mesmo constitui em dar apoio à Equipe de saúde da família. O nutricionista, enquanto membro da equipe do Nasf, prioritariamente desenvolve as suas ações com a Equipe da SF de sua área de abrangência. São atribuições desse profissional o atendimento clínico individual, trabalhos em grupos, projeto terapêutico singular, projeto saúde no território, clínica ampliada, visitas domiciliares, interconsultas, compartilhamento de caso com equipe, dentre outras (BRASIL, 2010). Essencial seria o nutricionista compor a ESF, posto que as ações referentes à alimentação e nutrição ficam sem ser abordadas de maneira sistemática. O relato de uma enfermeira mostrou seu sentimento de frustração diante das diversas perguntas sobre alimentação e nutrição que ficam sem respostas, por não ter apropriação dessa ciência. 
Percebemos, durante esses encontros, um pouco sobre nós, que tínhamos criado uma série de expectativas em relação ao projeto, dedicado horas para a sua construção, e nos questionado sobre o que os profissionais de saúde e o público da pesquisa iriam pensar. Podemos, enfim, transmitir o significado do projeto e ter uma boa aceitação de todos. Não foi apenas conhecimentos transmitidos, como profissionais e como pessoas também aprendemos muito com essas mamães. Mesmo as adolescentes ou as mais maduras expressavam uma maneira distinta de lidar com as dificuldades, sempre sorrindo, felizes a espera de uma criança saudável.

A participação na realização de todas as atividades gerou um maior entendimento e compreensão dos conceitos. Notou-se isso por meio da dinâmica das maçãs. As gestantes demonstravam entendimento ao levantar a maçã verde; quando levantavam a maçã vermelha era novamente esclarecido sobre o assunto abordado em cada encontro. O grupo foi participativo e apreciou o que foi discutido, pois começaram a compreender a importância de ter uma alimentação adequada para melhorar a saúde e a qualidade de vida.

\section{CONSIDERAÇÕES FINAIS}

O presente estudo apresentou a estruturação de um programa educativo para a prevenção da obesidade infantil desde a concepção com um grupo de gestantes. A pesquisa se mostrou útil para a melhoria do grau de conhecimento das participantes sobre o enfrentamento da obesidade como uma doença e a adoção de uma alimentação adequada com enfoque no período gestacional e alimentação de crianças menores de dois anos.

A partir das vivências e percepções observadas, o Aconselhamento Nutricional se mostrou essencial, sabendo que a prevenção é o melhor caminho. A prevenção deveria começar na infância, na vida intrauterina. As gestantes devem receber todo o apoio durante o período gestacional não somente com o acompanhamento no pré-natal, mas também com a participação em grupos de gestantes.

Vale ressaltar que, para controlar os fatores de risco que levam à obesidade, a alimentação adequada da gestante e a prática de atividade física moderada são de suma importância. Em relação ao bebê, se começa pela amamentação materna exclusiva até os seis meses, e continuação com a alimentação complementar e aleitamento até os dois anos. É de grande valia a atuação do nutricionista no acompanhamento tanto individual quanto coletivo, reforçando as neces- sidades do profissional fazendo parte da Equipe de Saúde da Família para atuar de forma mais eficaz e reduzir os problemas relacionados a má alimentação e má nutrição que acomete a nossa realidade. Deve-se dar atenção à prevenção com desenvolvimento de estratégias preventivas em todas as fases do ciclo da vida, principalmente na infância.

\section{REFERÊNCIAS}

ANDRETO, L. M. et al. Fatores associados ao ganho ponderal excessivo em gestantes atendidas em um serviço público de pré-natal na cidade de Recife, Pernambuco, Brasil. Cad. Saúde Pública, Rio de Janeiro, vol. 22, n. 11, 2006.

ASSOCIAÇÃO BRASILEIRA PARA O ESTUDO DA OBESIDADE E DA SÍNDROME METABÓLICA - (Abeso). In: MELO, Maria Edna. Doenças desencadeadas ou agravadas pela obesidade. 2011. Disponível em: <http://www.abeso.org.br/artigos>. Acesso em: 17 out. 2017.

BRASIL. Decreto Lei no 8.234, de 17 de setembro de 1991. Regulamenta a profissão nutricionista e determina outras providências. Brasília, DF, 1991. Disponível em: <http:// www.planalto.gov.br/ccivil_03/leis/1989_1994/L8234>. Acesso em: jan. 2018.

. Ministério da Saúde. Sala de Apoio à Gestão Estratégica (Sage), 2010. Disponível em: <http://189.28.128.178/ sage/>. Acesso em: 9 out. 2017.

. Ministério da Saúde. Secretaria de Atenção à Saúde. Departamento de Atenção Básica. Orientações para a coleta e análise de dados antropométricos em serviços de saúde: Norma Técnica do Sistema de Vigilância Alimentar e Nutricional - Sisvan. Brasília, DF: MS, 2011. p. 76. (Série G. Estatística e Informação em Saúde).

. Ministério da Saúde. Secretaria de Atenção à Saúde. Departamento de Atenção Básica. Guia alimentar para a população brasileira. 2. ed. Brasília, DF: MS, 2014. p. 156. COUTINHO, W. F. Consenso Latino-Americano de obesidade. Arquivos Brasileiros de Endocrinologia \& Metabologia, São Paulo, vol. 43, n. 1, fev. 1999. Disponível em: $<$ http://www.scielo.br/scielo.php?script=sci_arttext\&pi$\mathrm{d}=\mathrm{S} 000427301999000100006 \& \operatorname{lng}=e n \& n r m=i s o>$. Acesso em: 20 nov. 2017.

CRESWELL, J. W. Projeto de pesquisa: métodos qualitativo, quantitativo e misto. 3. ed. Porto Alegre: Artmed, 2010.

DELFINO, M. R. R. et al. O processo de cuidar participante com um grupo de gestantes: repercussões na saúde integral individual-coletiva. Ciência \& Saúde Coletiva, vol. 9, ed. 4, p. 1.057-1.066, 2004.

FERREIRA, H. da S. Redação de trabalhos acadêmicos nas áreas das ciências biológicas e da Saúde. Rio de Janeiro: Rubio, 2011.

FIGUEIREDO, J.; MACHADO, E. S.; SANTOS, H. Observação incorporada no Saara. Programa de Pós-Graduação em Arquitetura. Rio de Janeiro: UFRJ, 2007. 
INSTITUTO BRASILEIRO DE GEOGRAFIA E ESTATÍSTICA (IBGE). Censo 2010. Disponível em: <www.ibge.gov.br/cidadesat/topwindow.htm?1>. Acesso em: 9 dez. 2017.

. Ministério do Planejamento, Orçamento e Gestão. Diretoria de Pesquisas. Coordenação de Trabalho e Rendimento. Pesquisa Nacional de Saúde 2013 - Percepção do estado de saúde, estilos de vida e doenças crônicas. Brasil, Grandes regiões e Unidades da federação. Rio de Janeiro, 2014. p. 181. Disponível em: <http://ftp.ibge.gov.br/ PNS/2013/pns2013.pdf>. Acesso em: jan. 2018.

MARCONDES, E. et al. Pediatria Básica - Tomo I - Pediatria Geral e Neonatal. São Paulo: Sarvier, v. 1, 9. ed., 2002, 371 p. MELERE, C. et al. Índice de alimentação saudável para gestantes: adaptação para uso em gestantes brasileiras. Revista Saúde Pública, v. 47, n. 1, p. 20-28, 2013.

MUITO ALÉM DO PESO. Direção Estela Renner. Produção Marcos Nisti e Juliana Borges. Brasil, 2012. Maria Farinha Filmes. Disponível em: <www.muitoalemdopeso.com.br>. Acesso em: 10 dez. 2017.

PICCININI, C. A. et al. Gestação e a constituição da maternidade. Psicologia em Estudo, vol. 13, n. 1, p. 63-72, 2008.

RHEINGANTZ, P. A. et al. Observando a qualidade do lugar: procedimentos para a avaliação pós-ocupação. Rio de Janeiro: Universidade Federal do Rio de Janeiro; Faculdade de Arquitetura e Urbanismo; Pós-Graduação em Arquitetura, 2009. p. 117.

ROSSI, A.; MOREIRA, E. A.; RAUEN, M. S. Determinantes do comportamento alimentar: uma revisão com enfoque na família. Revista Nutrição, Campinas, vol. 21, n. 6, 2008.

SOARES, L. D.; PETROSKI, E. L. Prevalência, fatores etiológicos e tratamento da obesidade infantil. Revista Brasileira de Cineantropometria e Desempenho Humano, vol. 5, n. 1, p. 63-74, 2003.

SOCIEDADE BRASILEIRA DE PEDIATRIA (SBP). Obesidade na infância e adolescência - manual de orientação. 2. ed. São Paulo: Departamento Científico de Nutrologia, 2012. 